Review

\title{
Application of DMSP/OLS Nighttime Light Images: A Meta-Analysis and a Systematic Literature Review
}

\author{
Qingxu Huang ${ }^{1, *}$, Xi Yang ${ }^{2,3, \dagger}$, Bin Gao ${ }^{1, \dagger}$, Yang Yang ${ }^{4, \dagger}$ and Yuanyuan Zhao ${ }^{5, \dagger}$
}

1 State Key Laboratory of Earth Surface Processes and Resource Ecology, Beijing Normal University, 19 Xinjiekouwai Street, Beijing 100875, China; E-Mail: bing0402@126.com

2 Department of Geological Sciences, Brown University, Providence, RI 02912, USA; E-Mails: Xi_Yang@Brown.edu

3 The Ecosystems Center, Marine Biological Laboratory, Woods Hole, MA 02543, USA

4 School of Law and Political Science, Ocean University of China, Qingdao 266100, China; E-Mail: yang_ouc@163.com

5 Key Laboratory of Soil and Water Conservation and Desertification Combating; School of Soil and Water Conservation, Beijing Forestry University, Beijing 100083, China; E-Mail: yuanyuan0402@126.com

$\dagger$ These authors contributed equally to this work.

* Author to whom correspondence should be addressed; E-Mail: qxhuang@bnu.edu.cn; Tel.: +86-10-5880-4921; Fax: +86-10-5880-8661.

Received: 14 June 2014; in revised form: 18 July 2014 / Accepted: 18 July 2014 /

Published: 25 July 2014

\begin{abstract}
Since the release of the digital archives of Defense Meteorological Satellite Program Operational Line Scanner (DMSP/OLS) nighttime light data in 1992, a variety of datasets based on this database have been produced and applied to monitor and analyze human activities and natural phenomena. However, differences among these datasets and how they have been applied may potentially confuse researchers working with these data. In this paper, we review the ways in which data from DMSP/OLS nighttime light images have been applied over the past two decades, focusing on differences in data processing, research trends, and the methods used among the different application areas. Five main datasets extracted from this database have led to many studies in various research areas over the last 20 years, and each dataset has its own strengths and limitations. The number of publications based on this database and the diversity of authors and institutions involved have shown promising growth. In addition, researchers have accumulated vast experience
\end{abstract}


retrieving data on the spatial and temporal dynamics of settlement, demographics, and socioeconomic parameters, which are "hotspot" applications in this field. Researchers continue to develop novel ways to extract more information from the DMSP/OLS database and apply the data to interdisciplinary research topics. We believe that DMSP/OLS nighttime light data will play an important role in monitoring and analyzing human activities and natural phenomena from space in the future, particularly over the long term. A transparent platform that encourages data sharing, communication, and discussion of extraction methods and synthesis activities will benefit researchers as well as public and political stakeholders.

Keywords: DMSP/OLS nighttime light data; application; review; meta-analysis

\section{Introduction}

The Defense Meteorological Satellite Program Operational Line Scanner (DMSP/OLS) was originally used to detect the global distribution of clouds and cloud top temperatures in the early 1970s. Croft [1] reported that nighttime photographs of the Visible and Near-Infrared (VNIR) band from this sensor had the potential to observe a series of faint VNIR emission sources, such as city lights, auroras, gas flares, and fires. However, the first 20 years of images were recorded on filmstrips, which greatly impeded the accessibility and application of these datasets [2,3]. Since the establishment of a digital archive in 1992 by the National Oceanic and Atmospheric Administration/National Geophysical Data Center (NOAA/NGDC), these nighttime data have been widely exploited by the scientific community.

During the last two decades, nine satellites (i.e., from F10 to F18) carrying the OLS have been launched and used to collect nighttime images. Several different datasets, ranging from daily raw data to time-series "stable light" data, have been developed and applied to various observation areas. Popular applications of the DMSP/OLS nighttime images include monitoring human settlement [4,5]; estimating urban population [6] and population density [7], socio-economic activity [8], energy and electricity consumption [9], and gas emissions [10]; measuring impacts of urban growth on the environment [11]; detecting nocturnal fishing vessels [12]; mapping nighttime sky brightness [13] and forest fires [14]; assessing effects of emissions on ecosystem and human health $[15,16]$; and evaluating damage from natural disasters [17] and military action during wars [18].

While the applications of DMSP/OLS nighttime light images have diversified over time, the disadvantages of these images are widely acknowledged, and the Visible Infrared Imager Radiometer Suite (VIIRS) of the National Polar-Orbiting Operational Environmental Satellite System (NPOESS) was launched in 2011 to collect nighttime images of improved quality [19]. Scientific studies based on VIIRS nighttime images are currently in the infant stage because of the lesser-established data-processing methods, and the extracted datasets do not meet the long-term time series requirements of some research. DMSP/OLS nighttime light images remain the dominant source for observations of nighttime VNIR emissions, but there has not been a comprehensive review of the applications of DMSP/OLS nighttime light images. Specifically, readers and even some users of the DMSP/OLS database may be confused by the differences among the various datasets and their suitability for different research objectives (e.g., the digital values in "stable light" dataset and time series dataset of 
the DMSP/OLS data have the same range but represent different light information), and may not have a concrete understanding of the status quo and research trends related to the datasets.

Given the recent launch of the new VIIRS, this paper presents a review of the applications of DMSP/OLS nighttime light images over the past two decades. The purpose of this review is threefold. First, for novices using the DMSP/OLS nighttime light data, this review provides guidance on the pros and cons of different datasets of nighttime light data, and choosing the appropriate dataset. Second, for experienced researchers using these datasets, this paper provides an overall perspective on research trends and gaps, which can inspire more in-depth or interdisciplinary analysis based on these datasets. Third, for producers of different versions of data product, this study can help identify the most pressing technical challenges on preprocessing of the original data and developing algorithms for retrieving information from the data.

Our principal focus is on the differences in data processing, research trends, and methods used among the different application areas. In addition, we provide a general discussion on the prospective uses of DMSP/OLS nighttime light images. To make valid comparisons among applications, the following three criteria were used to select publications from the ISI Web of Knowledge: (1) a web search using the terms and Boolean operators "DMSP" or "OLS" or "nighttime light(s)" or "night light(s)" or "night-time light(s)"; (2) DMSP/OLS nighttime light images are the main data source; and (3) results that were published in journals and other outlets contained in the Scientific Citation Index Expanded (SCI/E) and Social Science Citation Index (SSCI) bibliographic databases between 1992 and 2013.

After removing articles that failed to meet these criteria, we narrowed the original 189 articles identified by the search terms (on 29 June 2014) to the 144 articles included in this review for in-depth analysis (A list of the 144 articles can be found in the supplementary material). The remainder of this paper is organized as follows. We present a general summary of the characteristics of DMSP/OLS nighttime images in Section 2, followed by an examination of the features of the different datasets in Section 3. An analysis of research outputs based on the selected 144 articles is provided in Section 4. We summarize methods used to extract information from DMSP/OLS nighttime light images among various research areas in Section 5. Finally, we offer a general perspective on the remaining challenges to applying data extracted from DMSP/OLS nighttime images in Section 6 and a conclusion in Section 7.

\section{Characteristics of DMSP/OLS nighttime images}

The OLS is an oscillating scan radiometer with two broad spectral bands: the Visible Near-Infrared (VNIR, 580 910 nm Full Width at Half Maximum (FWHM)) and Thermal Infrared (TIR, 1030 1290 nm FWHM). The current OLS system has been operated by the USA Air Force DMSP since 1976 [20]. Nighttime images are collected using the VNIR band, which is intensified by a photomultiplier tube to detect radiance emission down to the $5 \mathrm{E}^{-1 \circ} \mathrm{Watts} / \mathrm{cm}^{2} / \mathrm{sr}$ range. There are two spatial resolutions of nighttime images: "fine" resolution data have a nominal spatial resolution of $0.56 \mathrm{~km}$, while "smooth" data have a nominal spatial resolution of $2.7 \mathrm{~km}$ with $5 \times 5$ block averaging.

Given the sensitivity of the sensor at night, DMSP/OLS data can be used as a proxy to detect a variety of VNIR emissions. The availability of long-term daily data with moderate spatial resolution (e.g., $1 \mathrm{~km}$ ) has enabled researchers to explore a series of global, national, and regional research 
questions; in particular, the free download of the long-term Version 4 dataset since 2010 has significantly increased the use of these data. DMSP/OLS nighttime data have been used to directly observe natural phenomena (e.g., forest fires) and estimate social, demographic, and economic changes in lit areas, and have also been used indirectly as an ancillary database to facilitate other studies. A more detailed summary is provided in Section 5.

Although the advantages of nighttime DMSP/OLS data are commonly recognized, several disadvantages in using this sensor to observe nighttime emissions have been identified [20]. These include the (1) relatively low spatial resolution; (2) absence of onboard calibration; (3) lack of inter-satellite calibration; (4) lack of records of in-flight gain changes; (5) limited 6-bit quantization of digital numbers; (6) light saturation in highly populated urban centers because of the standard operation at the high gain setting; (7) the blooming effect (i.e., overestimation of lit area) due to the coarse spatial resolution of data and reflectance of light from adjacent areas (e.g., water bodies); and (8) limited accessibility to high-quality daily OLS data.

Several strategies were developed to overcome some of these shortcomings. For example, to overcome the lack of onboard calibration, Elvidge et al. [21] assembled a radiance-calibrated nighttime image of the United States acquired at reduced gain setting between March 1996 and February 1997. Compared to the previous 1994-1995 stable light data, the major advantage of this new dataset is providing detailed, brightness variations within lit areas and a detailed spatial distribution of nighttime light intensity. Empirical studies have proved that the radiance-calibrated data is a useful spatial indicator for energy related human activity (e.g., electric power consumption and greenhouse gas emission) [21] and urbanization related demographic and socioeconomic data [22]. In addition, the "light diffuse" phenomena in densely populated rural areas can be restrained to a certain extent [21]. However, the calibration procedure is complex and sensitive to some regional conditions (e.g., presence of snow cover in winter and vegetation phenology in spring and autumn [21]). Neither the algorithm nor the original time series nighttime light images can be accessed easily. Thus, only several radiance-calibrated datasets were produced at regional scales and for a few years [21,22].

Several methods were proposed to overcome the lack of inter-satellite calibration. These include the invariant region and the quadratic regression method proposed by Elvidge et al. [23], the second-order regression and optimal threshold method proposed by Liu et al. [24], and a power-law regression method proposed by Wu et al. [25]. Although studies based on these calibration methods showed performance improvement after the rectification [24,25], the assumption that the nighttime light remains stable over time in a particular area requires a careful choice of the invariant region manually.

In addition, researchers also developed different algorithms to overcome the saturation phenomenon in urban centers; for example, Raupach et al. [26] amplified the saturated light data based on a hypothesis of a power-law distribution of light density. Lo [22] developed a three-dimensional model to extract light volume using the triangulated irregular network functionality in ArcGIS. Letu et al. [27] used the 1996-1997 radiance-calibrated data, the 1999 stable light data, and the regression method for generating saturation-corrected data in 1999. Zhang et al. [28] proposed a method for combining nighttime data with MODIS NDVI data to reduce saturation effects in urban cores. All of these studies showed that using the saturation-calibrated data could improve the estimation of human activity and human impacts on the environment. However, in situ observations of the real distribution of 
light intensity within saturated areas are lacking, which will impede the validation of the saturation-calibrated data.

\section{Types of DMSP/OLS Datasets}

As mentioned in the previous section, researchers have developed various processing methods to generate appropriate datasets for studying a wide range of topics. Based on our review of the 144 selected articles, we found that five main datasets derived from the DMSP/OLS database are commonly used: "stable light" dataset, daily and monthly dataset, Version 4 time series dataset, radiance-calibrated dataset, and Asia light dataset (in order of the most utilized to date). The characteristics and representative applications of each dataset are provided in Table 1.

Table 1. Characteristics and usage of five commonly utilized datasets extracted from

DMSP/OLS nighttime images.

\begin{tabular}{|c|c|c|c|c|c|}
\hline & $\begin{array}{c}\text { Daily and } \\
\text { Monthly Dataset }\end{array}$ & $\begin{array}{c}\text { "Stable Light" } \\
\text { Dataset } \\
\end{array}$ & $\begin{array}{c}\text { Radiance-Calibrated } \\
\text { Dataset }\end{array}$ & $\begin{array}{c}\text { Time Series Dataset } \\
(\text { Version 1, 2, 4) }\end{array}$ & $\begin{array}{c}\text { Asia Light } \\
\text { Dataset }\end{array}$ \\
\hline Years & $\begin{array}{c}\text { Various days and } \\
\text { years }\end{array}$ & $\begin{array}{c}1994-1995 \text { and } \\
\text { other years }\end{array}$ & $\begin{array}{c}\text { 1996-1997 and } \\
\text { other years }\end{array}$ & $\begin{array}{c}\text { Version } 1 \text { (1992, 1993, 2000); } \\
\text { Version } 2 \text { (1992-2003); } \\
\text { Version } 4 \text { (1992-2012) }\end{array}$ & $\begin{array}{c}\text { 1992, 1996, 1998, } \\
\text { and other years }\end{array}$ \\
\hline $\begin{array}{l}\text { Temporal } \\
\text { resolution }\end{array}$ & $\begin{array}{l}\text { Daily and } \\
\text { monthly }\end{array}$ & Annual & Annual & Annual & Annual \\
\hline $\begin{array}{l}\text { Research } \\
\text { areas }\end{array}$ & $\begin{array}{l}\text { Forest fires, wars, } \\
\text { fishing vessels }\end{array}$ & $\begin{array}{l}\text { Urban extent and } \\
\text { its impacts; } \\
\text { socioeconomic } \\
\text { parameters }\end{array}$ & $\begin{array}{l}\text { Population density } \\
\text { at urban cores, } \\
\text { socioeconomic } \\
\text { parameters }\end{array}$ & $\begin{array}{c}\text { Temporal dynamics of social, } \\
\text { demographic, and } \\
\text { economic changes }\end{array}$ & $\begin{array}{l}\text { Urban expansion, } \\
\text { population density }\end{array}$ \\
\hline $\begin{array}{l}\text { Digital } \\
\text { number }\end{array}$ & Radiance & $\begin{array}{l}\text { Frequency of } \\
\text { light detected in } \\
\text { cloud-free data }\end{array}$ & Calibrated radiance & $\begin{array}{c}\text { Light intensity in stable } \\
\text { light areas }\end{array}$ & $\begin{array}{l}\text { Light intensity in } \\
\text { stable light areas }\end{array}$ \\
\hline $\begin{array}{l}\text { Number of } \\
\text { articles* }\end{array}$ & 41 & 48 & 23 & 33 & 2 \\
\hline
\end{tabular}

* The total number of publications is more than 132 because some studies used multiple datasets.

The most popular dataset, the "stable light" dataset, was originally developed by Elvidge et al. [29]. It was used in 48 of the selected articles. The earliest stable light dataset used the time series of cloud-free images from 1994 to 1995 to distinguish stable lights produced by cities, towns, and industrial facilities from ephemeral lights. The final output was a geo-referenced composite of nighttime stable light (NSL) images with a spatial resolution of $1 \mathrm{~km}$. These images record the percent frequency at which lights were detected, normalized by the number of cloud-free observations. Due to the high correlation between this dataset and the extent of urban area, it was widely used to estimate the spatial distribution of human activity globally and locally (e.g., urban expansion; [30]) and its impacts on soil [31]. However, a lack of light intensity in this dataset hindered further research on the intensity of human activities, such as population density. 
To overcome this shortcoming, Elvidge et al. [21] proposed a method for assembling the first radiance-calibrated annual dataset using images acquired between March 1996 and February 1997. This was the third most popular dataset, used by 23 of the 144 studies, and it uses data acquired through low- and high-gain settings in a time series fashion. It records spatial brightness variation within stable light areas and helps minimize the blooming effect that lights "diffuse" into neighboring cells. The additional spatial information on light intensity helps increase the accuracy of human activity estimations [32], and allows researchers to explore more research topics, especially in studies of urban areas that are mainly concerned with saturation [33].

The Version 4 DMSP/OLS Nighttime Lights Time Series dataset was recently developed by NOAA/NGDC. It was used by 33 of the 144 studies because it could be obtained directly and free of charge online as of January 2010. The files in this dataset are cloud-free annual composites from 1992 to 2012 with a spatial resolution of $1 \mathrm{~km}$; the dataset includes 33 annual composites because multiple satellites collected the same data in some years. It consists of three types of data: cloud-free coverage, NSL, and average visible data. Among these, the NSL dataset is most popular one because it removes background noise and records light intensity from cities and townships. The 1992-2012 time series was used to analyze the temporal dynamics of socioeconomic and demographic changes [34,35]. The most pressing challenge in using these datasets for long-term analysis is the calibration of the data [23], because the time series data are from six different satellites (F10, F12, F14, F15, F16, and F18) equipped with OLS sensors without onboard calibration. The absence of inter-satellite calibration and onboard calibration strongly limits the inter-annual comparability of light intensity represented by the digital number (DN) values. To overcome this limitation, different inter-calibration methods, largely based on an assumption that light intensity in some areas did not change throughout the timeframe of interest, were proposed by researchers [23-25,36].

A unique dataset of non-calibrated time series nighttime images was produced by the Japan National Institute of Environmental Studies and Tokyo University [37]. It contains extractions of light data for East Asia, which is of lower intensity and has less saturation than lights in developed Western countries. Based on the challenges identified with the stable light- and radiance-calibrated datasets, this dataset provides annual composites of average light intensity information extracted from stable light observations; as such, it combines stable light and light intensity but with less saturation. This dataset was used to map urban expansion [37] and model population density in China [38].

The final dataset to discuss is composed of daily raw images or monthly composites provided by NOAA/NGDC. Unlike the other four datasets, researchers used the data to observe some unstable and short-term light phenomena, such as fishing vessel dynamics in coastal areas [39], forest fires and burned areas in India [40], damage estimation of natural disasters [17], effects of violent conflicts on refugee movement [41], and detection of bioluminescence produced by colonies of bacteria in oceans [42]. However, the final datasets are not free, and their applications are strongly limited by the cost of each orbit of data and the complex preprocessing procedures.

\section{Research Trends Based on Selected Publications}

In this section, we present the research trends that emerged from the 144 articles, which were published in 61 journals between 1992 and 2013. Although the analyses based on these selected 
publications may not support a rigorous statistical conclusion, we believe that the trends found among these SCI/SSCI papers present a general picture of the research trends. We analyzed trends for the following aspects: publication and reference trends, published journals, author and institution productivity, and the top 10 most cited articles.

The number of publications showed an increasing trend from 1995 onward (Figure 1). There was a significant emergence of publications in 1997, which marked a new era of applications based on the newly assembled digital archived records of DMSP/OLS data. The number of publications continued to grow, from one added to the literature in 1998 to ten added in 2010. In the last 3 years of the time period considered, the number of publications increased more quickly, with 14 new papers added in 2011 and 24 added in 2013; this rapid growth coincided with the free access to the Version 4 DMSP/OLS Nighttime Lights Time Series dataset produced by NOAA/NGDC in 2010.

Figure 1. The number of publications from 1995 to 2013.

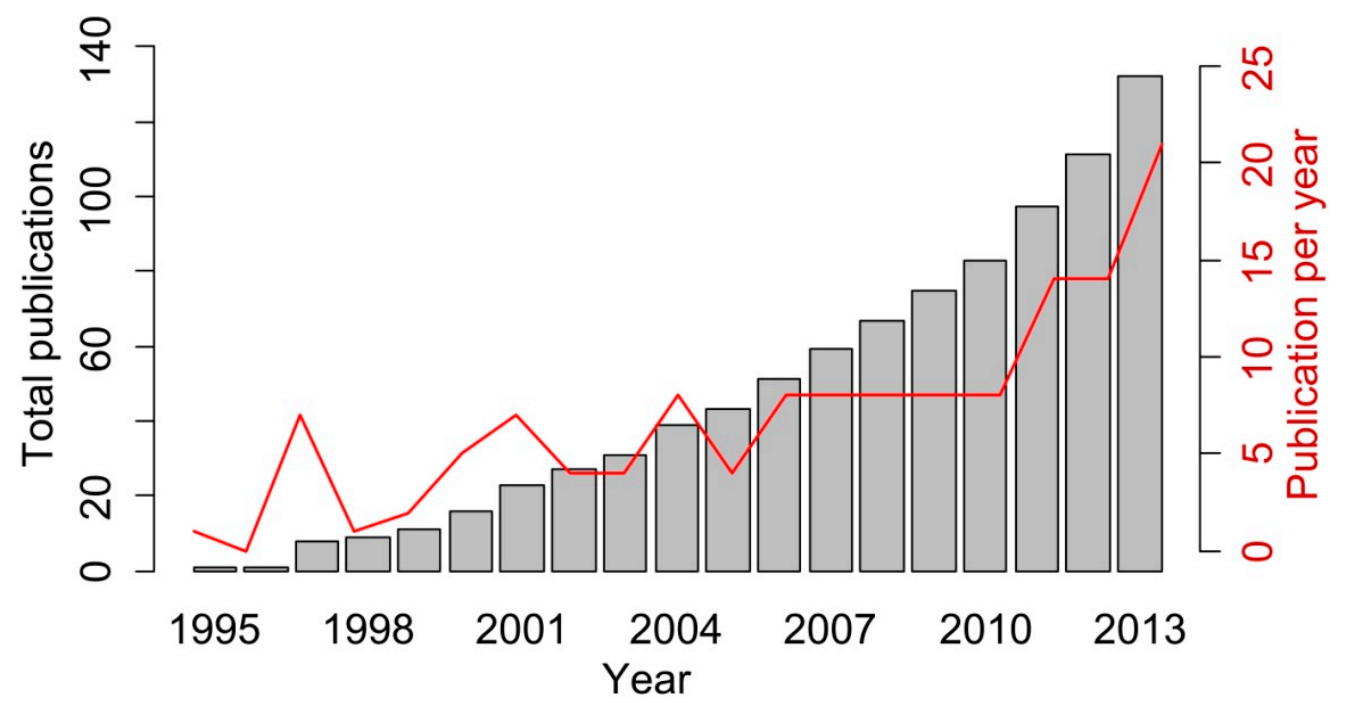

Studies based on DMSP/OLS nighttime images appeared in comprehensive journals that cover a wide variety of research areas (e.g., Science [43] and Proceedings of the National Academy of Sciences $[42,44])$ as well as professional journals that serve a more narrow research community (e.g., Remote Sensing of Environment, Monthly Notices of the Royal Astronomical Society, and Landscape and Urban Planning). Among the 62 journals, 9 published more than 3 research articles on DMSP/OLS data. A total of 75 articles were published by the 9 journals, accounting for nearly $70 \%$ of total citations. Two major publication outlets for research based on DMSP/OLS data were the International Journal of Remote Sensing and Remote Sensing of Environment; however, the top three most cited journals (measured by citation per paper, Table 2) were Photogrammetric Engineering and Remote Sensing, Monthly Notices of the Royal Astronomical Society, and Ecological Economics. It is worth noting that an open access journal, Remote Sensing, which began in 2009, had three publications in the field [45-47] and 12 citations from 2009 to 2013. On average, studies based on DMSP/OLS data from the nine journals have higher average citation than their impact factors calculated by ISI in 2013. This suggests that research based DMSP/OLS data has the potential to attract readers and boost communication. 
Table 2. The top eight most active journals publishing research based on DMSP/OLS data.

\begin{tabular}{ccccccc}
\hline Journal & TP & TP\% & TC & TC\% & AC & IF \\
\hline International Journal of Remote Sensing & 30 & 20.83 & 490 & $16.26 \%$ & 16.33 & 1.14 \\
Remote Sensing of Environment & 20 & 13.89 & 636 & $21.10 \%$ & 31.80 & 5.10 \\
Photogrammetric Engineering and Remote Sensing & 6 & 4.17 & 561 & $18.61 \%$ & 93.50 & 1.80 \\
Monthly Notices of the Royal Astronomical Society & 5 & 3.47 & 191 & $6.34 \%$ & 38.20 & 5.52 \\
GIScience and Remote Sensing & 5 & 3.47 & 9 & $0.30 \%$ & 1.80 & 1.43 \\
Remote Sensing & 3 & 2.08 & 12 & $0.40 \%$ & 4.00 & 2.10 \\
Fisheries Research & 3 & 2.08 & 23 & $0.76 \%$ & 7.67 & 1.70 \\
Ecological Economics & 3 & 2.08 & 127 & $4.21 \%$ & 42.33 & 2.86 \\
Sum & 144 & 52.08 & 3014 & 67.98 & 20.93 & N/A \\
\hline
\end{tabular}

TP: number of publications, TC: citation count, AC: average citation count per article, IF: impact factor

Consistent with observations in other fields, a small number of authors and institutions contributed to a significant share of publications. A total of 344 authors were listed on the 144 published manuscripts, and among them, 14 authors were listed more than five times (Table 3). A total of 67 publications included at least 1 of these 14 authors. In other words, $4.1 \%$ of all authors included in this sample of articles produced $46.5 \%$ of all publications. Prolific authors will accordingly promote the productivity of their institutions, and as such, the trends at the institutional level were similar. There were 154 different institutions listed among the 144 manuscripts, and 9 published more than 6 papers in this research field (Table 4). A total of 75 publications included at least one of these institutions, meaning that $5.8 \%$ of all institutions included in the sample accounted for $52.1 \%$ of all publications. The relative concentration of productive authors and institutions was due to two main factors. First, the accessibility of DMSP/OLS nighttime images was largely limited before the free online release of Version 4 data in 2010. The original products were processed at NOAA/NGDC by a group of researchers led by Professor Christopher Elvidge, the most productive institution and author (measured by total publications, Tables 3 and 4), respectively. Second, the range of applications based on DMSP/OLS nighttime light images was relatively narrow, mainly focusing on urban socioeconomic parameters. Some institutions that have access to this database need spatially and temporally matched statistical data or ground observation data to validate the DMSP/OLS data when applied to certain topics. These include studies on urban dynamics and populations from Beijing Normal University and the Chinese Academy of Science, and research on forest fires and aerosol properties from the Department of Space, Government of India.

The top 10 most-cited articles [8,10,21,29,31,48-52] share several similarities. First, all were published prior to 2002 (Table 5). This is not surprising, as citations increase over time. Four top 10 articles were published in 1997, which marked a new era of research using nighttime images. The top 10 articles could be classified into three categories. The first category included papers describing the data processing methods that produced composites of nighttime images, which have great potential for observing human activities. For instance, the second ranked paper provided the method for developing a stable light image from 236 orbits between 1994 and 1995 [29]. In addition, the third ranked paper provided the earliest radiance-calibrated light image between 1996 and 1997 [21]. These two datasets were widely used by other researchers among following publication. The second category was review papers that summarized the progress of research and offered critical perspectives on research 
development; for example, the eighth ranked paper offered a relatively comprehensive review of environmental applications of the stable light dataset and discussed their potential advantages and disadvantages [49]. The third category of papers represented the early adoption of DMSP/OLS nighttime images in specific application areas. All of the remaining 7 papers in the top 10 list belong to this category; these include the first ranked paper, which mapped socioeconomic parameters and greenhouse gas emissions [10], and the fourth ranked paper, which mapped urban areas [48].

Table 3. Top eight most productive authors.

\begin{tabular}{ccc}
\hline Rank & Author & Number of Publications \\
\hline 1 & Elvidge, C. & 43 \\
2 & Sutton, P. & 16 \\
3 & Baugh, Kimberly E. & 15 \\
4 & Badarinath, K.V.S. & 11 \\
5 & Tuttle, B.T. & 10 \\
6 & Kharol, S.K.; Ghosh, Tilottama; Seto, Karen C. & 7 \\
7 & Cinzano, P. & 6 \\
8 & Prasad, V.K.; Hobson, V.R.; Chand, T.R.K.; Imhoff, M.L.; Small, C. & 5 \\
\hline
\end{tabular}

Table 4. Top seven most productive institutions.

\begin{tabular}{ccc}
\hline \multirow{2}{*}{ Rank } & Institution & $\begin{array}{c}\text { Number of } \\
\text { Publications }\end{array}$ \\
\hline 1 & National Oceanic and Atmospheric Administration's National Geophysical Data Center & 47 \\
2 & University of Colorado & 20 \\
3 & University of Denver & 13 \\
4 & Colorado State University & 10 \\
5 & Yale University; Beijing Normal University & 8 \\
6 & Chinese Academy of Science; Department of Space, Government of India & 7 \\
7 & Columbia University & 6 \\
\hline
\end{tabular}

In summary, the number of publications on this research topic has increased steadily over the past two decades. Although a number of journals, authors, and institutions have dominated the number and influence of publications, increasing numbers of journals, authors, and institutions around the world have recognized the research potential of DMSP/OLS nighttime images and have attempted to fully explore these datasets. The growing trend of publications was fueled by the release of different datasets and their application to different research areas. Therefore, we encoded the 144 publications by dataset (daily and monthly, stable light, radiance-calibrated, Version 4 time series, and Asia light datasets) and research area (e.g., urban extent, demographic features, socioeconomic parameters, fire detection) to further analyze how the DMSP/OLS database of images has been utilized. 
Table 5. Top 10 most-cited articles.

\begin{tabular}{|c|c|c|c|}
\hline Rank & Article & Citations & Year \\
\hline 1 & $\begin{array}{l}\text { Night-time imagery as a tool for global mapping of socioeconomic parameters and greenhouse } \\
\text { gas emissions }\end{array}$ & 206 & 2000 \\
\hline 2 & Mapping city lights with nighttime data from the DMSP operational linescan system & 197 & 1997 \\
\hline 3 & $\begin{array}{l}\text { Radiance calibration of DMSP/OLS low-light imaging data } \\
\text { of human settlements }\end{array}$ & 112 & 1999 \\
\hline 4 & A technique for using composite DMSP/OLS "city lights" satellite data to map urban area & 109 & 1997 \\
\hline 5 & The first World Atlas of the artificial night sky brightness & 107 & 2001 \\
\hline 6 & $\begin{array}{l}\text { Relation between satellite observed visible-near infrared emissions, population, economic } \\
\text { activity and electric power consumption }\end{array}$ & 98 & 1997 \\
\hline 7 & $\begin{array}{l}\text { Census from Heaven: An estimate of the global human population using night-time satellite } \\
\text { imagery }\end{array}$ & 92 & 2001 \\
\hline 8 & Night-time lights of the world: 1994-1995 & 89 & 2001 \\
\hline 9 & $\begin{array}{l}\text { Global estimates of market and non-market values derived from nighttime satellite imagery, } \\
\text { land cover, and ecosystem service valuation }\end{array}$ & 82 & 2002 \\
\hline 10 & $\begin{array}{l}\text { Using nighttime DMSP/OLS images of city lights to estimate the impact of urban land use on } \\
\text { soil resources in the United States }\end{array}$ & 81 & 1997 \\
\hline
\end{tabular}

\section{Application Fields and Methods}

Based on the characteristics of the different datasets derived from the DMSP/OLS database, researchers have applied each to a variety of research topics. We generated a "word cloud" based on the titles and abstracts of all 144 publications to summarize the general and predominant research themes (Figure 2): the terms urban, population, area(s), spatial, global, cities, China, land, consumption, distribution, fire, economic, and emission were among the most commonly used. This indicates that most studies adopted nighttime datasets to explore human activity and its impacts on the environment in urban areas at national and global scales. Summarizing the research topics of the 144 papers, these studies were divided into 4 categories and 10 subcategories (Table 6). The four categories were (1) settlement dynamics and their impacts on the environment; (2) demographic and socioeconomic information; (3) short-term light monitoring; and (4) miscellaneous topics.

\subsection{Settlement Dynamics and Impacts on the Environment}

The first category of applications was the mapping of settlements (Figure 3), including urban areas [24,48,53], built-up areas [54], impervious surfaces areas [55], and urban boundaries [30]. This category included subcategories I and II (Table 6), and appeared in 40 papers. The major challenges of this research topic were distinguishing settlement light from short-term light, and reducing the blooming effect at the city edge, which may exaggerate the extent of settlement. The first strategy was the threshold method originally proposed by Imhoff [48], which compared changes in polygon perimeter along the increase in threshold. The best threshold yielded the highest accuracy with urban areas from U.S. census data; however, the optimal threshold in this study, $89 \%$ for American cities, is not a universal value for other cities around the world, especially in developing countries where the average light intensity is weaker than in developed countries [55]. In addition, the level of development 
in countries such as China is spatially heterogeneous, and thus different regional thresholds are required to increase mapping accuracy [56]. The threshold based on calibrated radiance is easier to interpret than that based on stable light data [30].

Figure 2. Word cloud generated by Wordle (http://www.wordle.net/) using words in the titles and abstracts from the selected 144 articles. The size of each word is indicative of its relative frequency of occurrence.

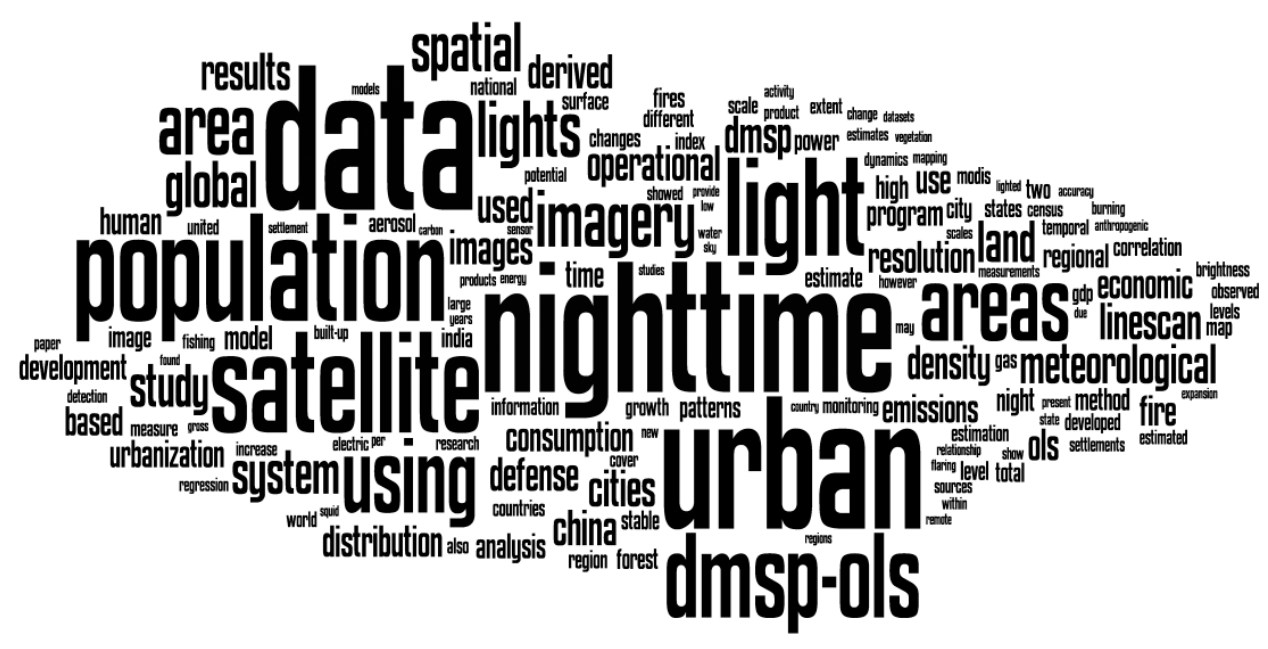

Table 6. Applications of DMSP/OLS nighttime images for different research topics.

\begin{tabular}{|c|c|c|c|}
\hline Major Categories & Subcategory & Research Topics & $\begin{array}{c}\text { Number of } \\
\text { Publications * }\end{array}$ \\
\hline \multirow{2}{*}{$\begin{array}{l}\text { Settlement } \\
\text { dynamics and } \\
\text { impacts on } \\
\text { the environment }\end{array}$} & I & $\begin{array}{l}\text { Urban land dynamics (e.g., urban extent, urban boundary, } \\
\text { impervious surface areas, and built-up infrastructure) }\end{array}$ & 28 \\
\hline & II & $\begin{array}{l}\text { Impacts of urbanization on soil, net primary productivity, } \\
\text { urban surface temperature and surface air temperature }\end{array}$ & 12 \\
\hline \multirow{3}{*}{$\begin{array}{c}\text { Demographic and } \\
\text { socioeconomic } \\
\text { information }\end{array}$} & III & $\begin{array}{l}\text { Demographic information (e.g., population, urban population, } \\
\text { population density, "ambient population") }\end{array}$ & 30 \\
\hline & IV & $\begin{array}{l}\text { Socioeconomic parameters (e.g., GDP, freight traffic, copper } \\
\text { stock, poverty index, per capital income) }\end{array}$ & 27 \\
\hline & $\mathrm{V}$ & Energy and electric power consumption & 15 \\
\hline \multirow{2}{*}{$\begin{array}{c}\text { Short-term } \\
\text { light monitoring }\end{array}$} & VI & $\begin{array}{c}\text { Short-term lighting (e.g., aerosol properties and forest fire, gas } \\
\text { flare, burning area and light flash) }\end{array}$ & 18 \\
\hline & VII & Fishing vessel monitoring & 7 \\
\hline \multirow[b]{3}{*}{ Other applications } & VIII & $\begin{array}{l}\text { Anthropogenic gas emission } \\
\text { (e.g., fossil fuel } \mathrm{CO}_{2} \text { and nitrogen oxide) }\end{array}$ & 8 \\
\hline & IX & Nighttime sky brightness and light pollution & 8 \\
\hline & $\mathrm{X}$ & $\begin{array}{l}\text { Other topics (human health, water footprint and virtual water, } \\
\text { wars and conflicts, scaling law of city size, biolumine } \\
\text { phenomena, coral reef stress, bird foraging, earthquake } \\
\text { damage, ecosystem services, and climate station classification) }\end{array}$ & 18 \\
\hline
\end{tabular}

\footnotetext{
* The total number of publications does not add up to 132 because some studies span multiple research areas.
} 
Figure 3. The dynamics of urban expansion in China derived from the DMSP/OLS nighttime light data from 1992 to 2008 (Source: Liu et al. [24]).

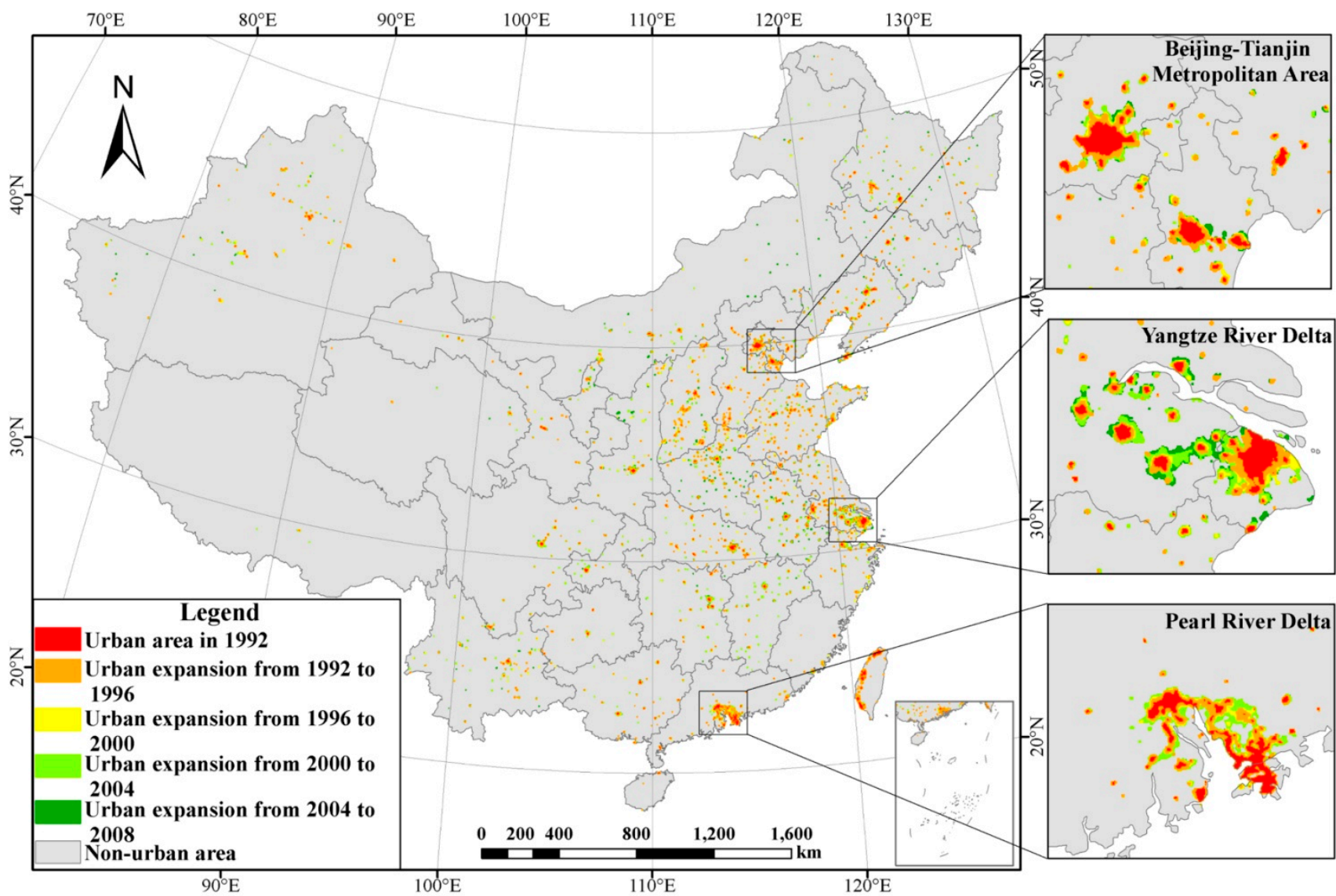

Another strategy is to integrate other sources of remote-sensing information to increase the mapping accuracy. For instance, Lu et al. [57] combined nighttime images and MODIS NDVI data to map human settlements in southeastern China. The results showed that the regression method integrating DMSP and NDVI data produced a more accurate estimation and spatial distribution of urban settlements than the results based on each dataset individually. Cao et al. [58] proposed a semi-automatic algorithm based on the support vector machine technique to extract urban areas by combining nighttime images with SPOT VGT data. They found that the new method achieved comparable results with localized thresholds in 25 Chinese cities and avoided the time-consuming procedure of finding the local optimal thresholds.

\subsection{Demographic and Socioeconomic Information}

The second category of application focused on inferring socioeconomic development from the DMSP/OLS database [59], as nighttime light images showed potential as a proxy for the intensity of human activity (Figure 4). Subcategories III, IV, and V belonged to this category, and included a total of 72 papers (Table 6). The two most common parameters extracted from the DMSP/OLS database were population (30 articles), GDP (18 papers), and energy and electric consumption (15 articles). Other parameters, such as income [60], copper stock [61], and freight traffic [62] also attracted researchers' attention. 
Figure 4. The scatter diagram showing the relationship between change rate of total nighttime light change rate and change rate of gross domestic product in Zimbabwe (Source: Li et al. [46]).

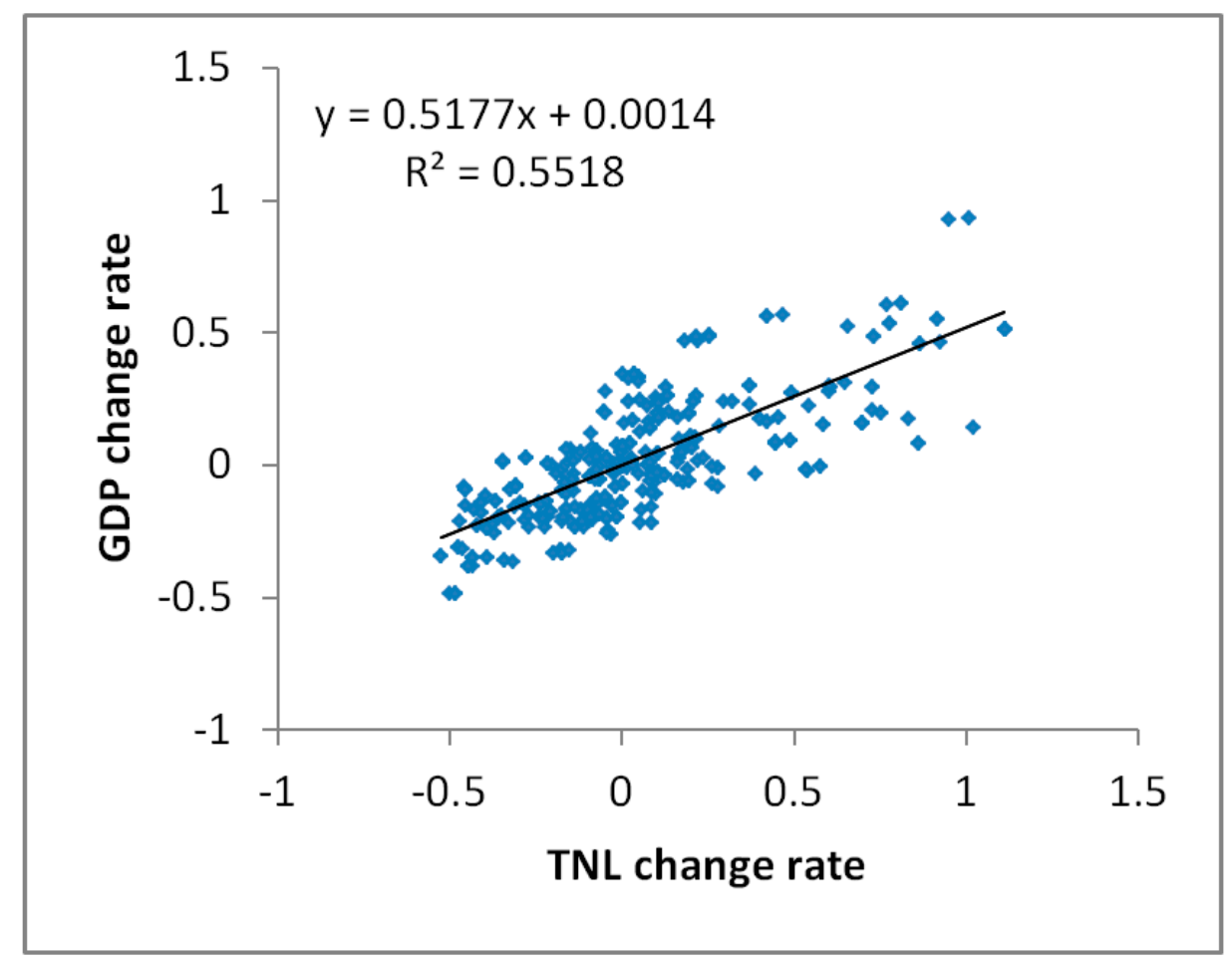

Studies on extracting demographic and socioeconomic information from DMSP/OLS nighttime images can be divided into two types. The first is to construct statistical relationships between nighttime light data and a particular aggregated parameter at a specific geographic extent, without considering the spatial distribution of this parameter. Lit areas and cumulative DN values within lit areas, as well as post-processed three-dimensional DN values, have been used to develop statistical models. The statistical methods also varied from linear regression to nonlinear regression; for example, He et al. [9] established a linear regression model between saturated corrected DN values of light images and electric power consumption in China, and yielded consistently reliable results for 2000-2008 compared to the original statistical data. Lo [22] proposed a method for constructing logarithmic regression models between urban indicators (i.e., GDP, build-up area, electricity consumption) and surface area as well as volume of light extracted from the triangulated irregular network functionality. The results showed that the volume of light performed slightly better than the surface area of light for estimating these parameters for 35 Chinese cities.

The second type of study is to map the distribution of particular parameters in space. The relationship between the light images and population density is a prevalent topic. Researchers have not only evaluated the relationship between light intensity distribution and population density from census data $[63,64]$, but have also used ancillary spatial information such as enhanced vegetation index and digital elevation models to improve the mapping accuracy. For example, Zhuo et al. [38] modeled population density in counties where light was too weak to detect based on Coulomb's Law with the electric field superposition principle, and digital elevation information. The results was consistent with census data and provided more spatial information on population density in China. The distribution of 
light intensity can be used to further estimate the density of energy consumption, greenhouse gas emissions, and economic activity.

In addition, DMSP/OLS nighttime images can be used as an ancillary proxy to assess the degree of development at different scales [65]. For example, a global poverty map was produced by combining DMSP/OLS data with the world population distribution from LandScan 2004 [66]. A provincial level poverty assessment was also carried out by comparing the integrated poverty index from statistical censuses with the average light index from DMSP/OLS data in China [67].

\subsection{Short-Term Light Monitoring}

Contrary to the aforementioned two categories of applications, studies on short-term light phenomena may focus on spatial and temporal dynamics of some unstable light, and even instantaneous lighting phenomena. Recent studies have included monitoring forest fires and their impacts on aerosol properties and burned areas [40,68], monitoring gas flares [69], detecting fishing vessels [70], and identifying lightning flashes [71]. The challenges in this category are threefold. First, the extraction method for isolating specific short-term lights from stable lights and other irrelevant short-term lights is underdeveloped. Using forest fire mapping as an example, researchers need to exclude long-term lights by masking out stable light pixels, and remove other light sources such as lightning, scan lines, and heavily lit clouds through visual and manual interpretation [68]. Second, short-term lighting phenomena can last from seconds to days, and from nighttime to daytime; thus, DMSP/OLS nighttime images alone cannot capture their complete process. For example, additional remotely sensed data sources such as MODIS, Indian Remote Sensing Satellite IRS-P6, and Advanced Wide Field Sensor were used to provide complementary and validating information on forest fire mapping during the daytime [40,72]. Third, accessibility to ground truth observations of short-term light phenomena is highly limited. For example, fishing vessels' logbooks can validate the fishing efforts extracted from DMSP/OLS images, but are difficult to acquire in most cases [73].

\subsection{Other Applications}

The final category of applications contained miscellaneous interdisciplinary research, and subcategories VIII to X fell into this category. The number of publications in this category was relatively small, because the research topics were mostly novel and interdisciplinary. Intuitively, the methods developed to extract this information were relatively immature or at the trial stage, but using DMSP/OLS nighttime light data to explore interdisciplinary themes in research remains promising.

For example, a key research area in climate science is assessing $\mathrm{CO}_{2}$ emissions from urban areas. Previous studies depended on the relationship between population and $\mathrm{CO}_{2}$ emission alone to map the spatial distribution of $\mathrm{CO}_{2}$ emission. Several studies started to combine nighttime lights and population together, which was found to be better than using population alone [74,75]. Several other studies combined $\mathrm{CO}_{2}$ emission from point sources like power plants with nighttime lights data, which was in agreement with existing inventory dataset $[76,77]$. DMSP/OLS nighttime light data in combination with spatially explicit estimation of $\mathrm{CO}_{2}$ concentrations from the Japanese Greenhouse Gases Observing Satellite have been used to understand the anthropogenic emissions of $\mathrm{CO}_{2}$ from megacities such as Los Angeles [78]. 
In addition to the above topic, nighttime lights data were used in more new areas (Table 6). By comparing the nighttime light loss after a major disaster such as earthquake, Kohiyama et al. [17] developed a system that provides timely (within $24 \mathrm{~h}$ ) information on the spatial distribution of the impacted urban area. Another example is that by comparing the nighttime lights intensity before and after certain military actions in Bagdad, Agnew et al. [18] assessed whether those military actions actually achieved their goals - to stabilize the region. We envision that more new areas of study will be using nighttime lights data in the near future, as this type of dataset accumulated and additional sensors provide finer spatial resolution.

\section{Discussion}

\subsection{Major Challenges}

Although enhanced nighttime images are currently collected by the new VIIRS sensor along with the OLS nighttime images, OLS nighttime images will still be a dominant data source for a large number of empirical applications as they provide a relatively consistent dataset on nighttime light over the past two decades. Based on how these data have been applied and considering the new data source from the VIIRS sensor, we argue that several challenges should be tackled.

First, ensuring the comparability and consistency of data will be a major obstacle. In our review, we found that the release of different datasets derived from the DMSP/OLS database increased the extent and depth of studies. However, even the latest Version 4 dataset has apparent limitations in terms of data comparability and consistency [23,79]. Thus, a new rigorous and robust dataset of long-term nighttime images after systematic inter-annual and inter-satellite calibrations could stimulate relevant studies. The tradeoff between loss of information after calibration and comparability before calibration is a noteworthy consideration. In addition, novel methods that can integrate OLS images with VIIRS images and guarantee their comparability will encourage the use of OLS images and VIIRS images simultaneously; this has the potential to prolong the availability of data for VIIRS images as well as enhance the spatial and spectral resolution of OLS images.

Second, new methods that improve data quality and performance need to be developed. While radiance-calibration and the reduction of blooming and saturation effects are two main ways to enhance the meaning and performance of these data, improving current methods for extracting expected information automatically and intelligently is also a potential research direction.

Third, comparative studies between OLS and VIIRS images will attract considerable attention. Although nighttime images collected from the VIIRS sensor have been released, empirical research based on these datasets is rare. Comparing results of studies on the same research topic between the old OLS images and the new VIIRS images will allow us to further understand the advancement and intrinsic limitations of the new database [80-84]. Therefore, it can answer a series of research questions, such as how does the VIIRS images perform in overcoming the saturation and blooming phenomena in OLS images; does the improved quality of VIIRS images contribute to better estimations of social-economic parameters, and how to fuse the data from the two sensors?

Fourth, fully exploring the potential of DMSP/OLS nighttime images from the perspective of multidisciplinary or interdisciplinary research will be a key research area. Interesting results and 
applications can be discovered by combining DMSP/OLS nighttime images with research from a broader range of disciplines. For example, a recent study has found a positive association between regional nighttime light intensity and the birth region of current political leaders worldwide [85]. The results supported the hypothesis of regional favoritism that some political leaders may make political decisions beneficial to their birth regions. Other examples can be found in modeling in-use steel stock in buildings and civil engineering infrastructure [86], monitoring trend of light pollution [87-90] and evaluating global armed conflicts [18,40,91].

Finally, we suggest that a transparent platform will be important for communicating and discussing application areas. This platform can collect different versions of processed nighttime images, open-source algorithm codes for different applications, and results under the same research target at different locations and scales. This will be beneficial for validating research results, improving existing extracting methods, and discovering and examining academic assumptions at different scales. Furthermore, this will improve the communication of research results within academia, and among scientists, the public, and political stakeholders.

\subsection{Uncertainties}

Although this paper reviews studies based on DMSP/OLS nighttime light data over the last two decades, a number of publications are not included in this review. They are papers in conference proceedings, book chapters, institution reports, and papers not indexed in SCI/SSCI database. The reason for the omission is that the quality of these papers may vary considerably. Some omitted publications may be too preliminary and lack rigorous conclusion. Whilst some of them may lack necessary details to repeat the study. Therefore, we analyzed characteristics of applications of DMSP/OLS nighttime light images based on the selected 144 papers. These selected papers may not capture the whole picture of applications, however, we believe that they still represent general features and research trends on applications of DMSP/OLS nighttime light images.

\section{Conclusions}

In this paper, we provided an evaluation of the applications of DMSP/OLS nighttime light data by comparing the strengths and weaknesses of different datasets derived from the database, analyzing trends in recent publications, and summarizing the common methods and difficulties associated with specific categories of applications. We found that five main datasets (stable light, daily and monthly, Version 4 time series, radiance-calibrated, and Asian light data) extracted from the nighttime light images were widely used to study four major categories of topics (a total of 144 papers) and were beneficial in some applications but limiting in others. Over the past two decades since 1995, the numbers of publications, authors, and institutions using DMSP/OLS nighttime lights have increased steadily, reflecting the release of the different types of databases. For example, the number of publications increased from 1 per year in 1995 to 24 per year in 2013. In addition, for each research area, researchers have developed various methods for retrieving spatial and temporal information from different datasets. Most studies have found significant correlations between recorded nighttime lit area and/or light intensity, and human activity and natural phenomena. We argue that, with the launch of the new generation of nighttime light detection sensor, challenges and opportunities exist for future 
applications based on nighttime light images. A transparent platform that shares different versions of post-processed images, promotes communication and discussion of different detection algorithms, and synthesizes results at different spatial and temporal scales will be beneficial to the academic world and beyond.

\section{Acknowledgments}

This work is supported by the 111 project "Hazard and Risk Science Base at Beijing Normal University" under Grant B08008 (Ministry of Education and State Administration of Foreign Experts Affairs, PRC), the State Key Laboratory of Earth Surface Processes and Resource Ecology of Beijing Normal University (No. 2013-RC-03), and the Fundamental Research Funds for the Central Universities (Grant No. 201413037). The authors also thank the efforts of anonymous reviewers and the editor for their valuable comments and suggestions to improve the quality of the paper.

\section{Author Contributions}

Qingxu Huang conceived and designed the review. Xi Yang, Bin Gao, Yang Yang, and Yuanyuan Zhao made substantial contributions to acquisition, analysis and interpretation of the meta-analysis. All authors discussed the basic structure of the manuscript, and Qingxu Huang finished the first draft. All authors reviewed and edited the draft, approved the submitted manuscript, and agreed to be listed and accepted the version for publication.

\section{Conflicts of Interest}

The authors declare no conflict of interest

\section{References}

1. Croft, T.A. Burning waste gas in oil fields. Nature 1973, 245, 375-376.

2. Sullivan, W.T. A $10 \mathrm{~km}$ resolution image of the entire night-time earth based on cloud-free satellite photographs in the 400-1100 nm band. Int. J. Remote Sens. 1989, 10, 1-5.

3. Welch, R. Monitoring urban population and energy utilization patterns from satellite data. Remote Sens. Environ. 1980, 9, 1-9.

4. Elvidge, C.; Baugh, K.; Hobson, V.; Kihn, E.; Kroehl, H.; Davis, E.; Cocero, D. Satellite inventory of human settlements using nocturnal radiation emissions: A contribution for the global toolchest. Glob. Chang. Biol. 1997, 3, 387-395.

5. Yu, B.; Shu, S.; Liu, H.; Song, W.; Wu, J.; Wang, L.; Chen, Z. Object-based spatial cluster analysis of urban landscape pattern using nighttime light satellite images: A case study of China. Int. J. Geogr. Inf. Sci. 2014, doi: 10.1080/13658816.2014.922186.

6. Dobson, J.E.; Brlght, E.A.; Coleman, P.R.; Durfee, R.C.; Worley, B.A. Landscan: A global population database for estimating populations at risk. Photogramm. Eng. Remote Sens. 2000, 66, 849-857. 
7. Sutton, P.; Roberts, D.; Elvidge, C.; Melj, H. A comparison of nighttime satellite imagery and population density for the continental united states. Photogramm. Eng. Remote Sens. 1997, 63, 1303-1313.

8. Sutton, P.C.; Costanza, R. Global estimates of market and non-market values derived from nighttime satellite imagery, land cover, and ecosystem service valuation. Ecol. Econ. 2002, 41, 509-527.

9. He, C.; Ma, Q.; Liu, Z.; Zhang, Q. Modeling the spatiotemporal dynamics of electric power consumption in mainland China using saturation-corrected DMSP/OLS nighttime stable light data. Int. J. Digit. Earth 2013, doi:10.1080/17538947.2013.822026.

10. Doll, C.N.H.; Muller, J.-P.; Elvidge, C.D. Night-time imagery as a tool for global mapping of socioeconomic parameters and greenhouse gas emissions. Ambio 2000, 29, 157-162.

11. Nizeyimana, E.L.; Petersen, G.W.; Imhoff, M.L.; Sinclair, H.R.; Waltman, S.W.; Reed-Margetan, D.S.; Levine, E.R.; Russo, J.M. Assessing the impact of land conversion to urban use on soils with different productivity levels in the USA. Soil Sci. Soc. Am. J. 2001, 65, $391-402$.

12. Cho, K.; Ito, R.; Shimoda, H.; Sakata, T. Technical note and cover fishing fleet lights and sea surface temperature distribution observed by DMSP/OLS sensor. Int. J. Remote Sens. 1999, 20,3-9.

13. Cinzano, P.; Falchi, F.; Elvidge, C.D.; Baugh, K.E. The artificial night sky brightness mapped from DMSP satellite operational linescan system measurements. Mon. Not. R. Astron. Soc. 2000, 318, 641-657.

14. Fuller, D.O.; Fulk, M. Comparison of noaa-avhrr and DMSP-OLS for operational fire monitoring in kalimantan, indonesia. Int. J. Remote Sens. 2000, 21, 181-187.

15. Aubrecht, C.; Elvidge, C.D.; Longcore, T.; Rich, C.; Safran, J.; Strong, A.E.; Eakin, C.M.; Baugh, K.E.; Tuttle, B.T.; Howard, A.T.; et al. A global inventory of coral reef stressors based on satellite observed nighttime lights. Geocarto Int. 2008, 23, 467-479.

16. Pauley, S.M. Lighting for the human circadian clock: Recent research indicates that lighting has become a public health issue. Med. Hypotheses 2004, 63, 588-596.

17. Kohiyama, M.; Hayashi, H.; Maki, N.; Higashida, M.; Kroehl, H.W.; Elvidge, C.D.; Hobson, V.R. Early damaged area estimation system using DMSP-OLS night-time imagery. Int. J. Remote Sens. 2004, 25, 2015-2036.

18. Agnew, J.; Gillespie, T.W.; Gonzalez, J.; Min, B. Baghdad nights: Evaluating the US military "surge" using nighttime light signatures. Environ. Plan. A 2008, 40, 2285-2295.

19. Schueler, C.F.; Lee, T.F.; Miller, S.D. VIIRS constant spatial-resolution advantages. Int. J. Remote Sens. 2013, 34, 5761-5777.

20. Elvidge, C.D.; Cinzano, P.; Pettit, D.R.; Arvesen, J.; Sutton, P.; Small, C.; Nemani, R.; Longcore, T.; Rich, C.; Safran, J.; et al. The Nightsat mission concept. Int. J. Remote Sens. 2007, 28, 2645-2670.

21. Elvidge, C.D.; Baugh, K.E.; Dietz, J.B.; Bland, T.; Sutton, P.C.; Kroehl, H.W. Radiance calibration of DMSP-OLS low-light imaging data of human settlements. Remote Sens. Environ. 1999, 68, 77-88. 
22. Lo, C.P. Modeling the population of China using DMSP operational linescan system nighttime data. Photogramm. Eng. Remote Sens. 2001, 67, 1037-1047.

23. Elvidge, C.; Ziskin, D.; Baugh, K.; Tuttle, B.; Ghosh, T.; Pack, D.; Erwin, E.; Zhizhin, M. A fifteen year record of global natural gas flaring derived from satellite data. Energies 2009, 2, 595-622.

24. Liu, Z.; He, C.; Zhang, Q.; Huang, Q.; Yang, Y. Extracting the dynamics of urban expansion in China using DMSP-OLS nighttime light data from 1992 to 2008. Landsc. Urban Plan. 2012, 106, $62-72$.

25. Wu, J.; He, S.; Peng, J.; Li, W.; Zhong, X. Intercalibration of DMSP-OLS night-time light data by the invariant region method. Int. J. Remote Sens. 2013, 34, 7356-7368.

26. Raupach, M.R.; Rayner, P.J.; Paget, M. Regional variations in spatial structure of nightlights, population density and fossil-fuel $\mathrm{CO}_{2}$ emissions. Energy Policy 2010, 38, 4756-4764.

27. Letu, H.; Hara, M.; Tana, G.; Nishio, F. A saturated light correction method for DMSP/OLS nighttime satellite imagery. IEEE Trans. Geosci. Remote Sens. 2012, 50, 389-396.

28. Zhang, Q.; Schaaf, C.; Seto, K.C. The vegetation adjusted ntl urban index: A new approach to reduce saturation and increase variation in nighttime luminosity. Remote Sens. Environ. 2013, 129, 32-41.

29. Elvidge, C.D.; Baugh, K.E.; Kihn, E.A.; Kroehl, H.W.; Davis, E.R. Mapping city lights with nighttime data from the DMSP operational linescan system. Photogramm. Eng. Remote Sens. 1997, 63, 727-734.

30. Henderson, M.; Yeh, E.T.; Gong, P.; Elvidge, C.; Baugh, K. Validation of urban boundaries derived from global night-time satellite imagery. Int. J. Remote Sens. 2003, 24, 595-609.

31. Imhoff, M.L.; Lawrence, W.T.; Elvidge, C.D.; Paul, T.; Levine, E.; Privalsky, M.V.; Brown, V. Using nighttime DMSP/OLS images of city lights to estimate the impact of urban land use on soil resources in the united states. Remote Sens. Environ. 1997, 59, 105-117.

32. Doll, C.N.H.; Muller, J.-P.; Morley, J.G. Mapping regional economic activity from night-time light satellite imagery. Ecol. Econ. 2006, 57, 75-92.

33. Lo, C.P. Urban indicators of China from radiance-calibrated digital DMSP-OLS nighttime images. Ann. Assoc. Am. Geogr. 2002, 92, 225-240.

34. Ma, T.; Zhou, C.; Pei, T.; Haynie, S.; Fan, J. Quantitative estimation of urbanization dynamics using time series of DMSP/OLS nighttime light data: A comparative case study from China's cities. Remote Sens. Environ. 2012, 124, 99-107.

35. Small, C.; Elvidge, C.D. Night on earth: Mapping decadal changes of anthropogenic night light in asia. Int. J. Appl. Earth Obs. Geoinf. 2013, 22, 40-52.

36. Li, X.; Chen, X.; Zhao, Y.; Xu, J.; Chen, F.; Li, H. Automatic intercalibration of night-time light imagery using robust regression. Remote Sens. Lett. 2013, 4, 45-54.

37. He, C.; Shi, P.; Li, J.; Chen, J.; Pan, Y.; Li, J.; Zhuo, L.; Ichinose, T. Restoring urbanization process in China in the 1990s by using non-radiance-calibrated DMSP/OLS nighttime light imagery and statistical data. Chin. Sci. Bull. 2006, 51, 1614-1620.

38. Zhuo, L.; Ichinose, T.; Zheng, J.; Chen, J.; Shi, P.J.; Li, X. Modelling the population density of China at the pixel level based on DMSP/OLS non-radiance-calibrated night-time light images. Int. J. Remote Sens. 2009, 30, 1003-1018. 
39. Waluda, C.M.; Yamashiro, C.; Elvidge, C.D.; Hobson, V.R.; Rodhouse, P.G. Quantifying light-fishing for dosidicus gigas in the eastern pacific using satellite remote sensing. Remote Sens. Environ. 2004, 91, 129-133.

40. Badarinath, K.V.S.; Sharma, A.R.; Kharol, S.K. Forest fire monitoring and burnt area mapping using satellite data: A study over the forest region of kerala state, india. Int. J. Remote Sens. 2011, $32,85-102$.

41. Witmer, F.; O'Loughlin, J. Detecting the effects of wars in the caucasus regions of russia and georgia using radiometrically normalized DMSP-OLS nighttime lights imagery. GISci. Remote Sens. 2011, 48, 478-500.

42. Miller, S.D.; Haddock, S.H.D.; Elvidge, C.D.; Lee, T.F. Detection of a bioluminescent milky sea from space. Proc. Natl. Acad. Sci. USA 2005, 102, 14181-14184.

43. Bharti, N.; Tatem, A.J.; Ferrari, M.J.; Grais, R.F.; Djibo, A.; Grenfell, B.T. Explaining seasonal fluctuations of measles in niger using nighttime lights imagery. Science 2011, 334, 1424-1427.

44. Chen, X.; Nordhaus, W.D. Using luminosity data as a proxy for economic statistics. Proc. Natl. Acad. Sci. 2011, 108, 8589-8594.

45. Ghosh, T.; Anderson, S.; Powell, R.L.P.; Sutton, P.; Elvidge, C. Estimation of Mexico's informal economy and remittances using nighttime imagery. Remote Sens. 2009, 1, 418-444.

46. Li, X.; Ge, L.; Chen, X. Detecting Zimbabwe's decadal economic decline using nighttime light imagery. Remote Sens. 2013, 5, 4551-4570.

47. Zhang, Q.; Seto, K. Can night-time light data identify typologies of urbanization? A global assessment of successes and failures. Remote Sens. 2013, 5, 3476-3494.

48. Imhoff, M.L.; Lawrence, W.T.; Stutzer, D.C.; Elvidge, C.D. A technique for using composite DMSP/OLS "city lights" satellite data to map urban area. Remote Sens. Environ. 1997, 61, 361-370.

49. Cinzano, P.; Falchi, F.; Elvidge, C.D. The first world atlas of the artificial night sky brightness. Mon. Not. R. Astron. Soc. 2001, 328, 689-707.

50. Elvidge, C.D.; Baugh, K.E.; Kihn, E.A.; Kroehl, H.W.; Davis, E.R.; Davis, C.W. Relation between satellite observed visible-near infrared emissions, population, economic activity and electric power consumption. Int. J. Remote Sens. 1997, 18, 1373-1379.

51. Sutton, P.; Roberts, D.; Elvidge, C.; Baugh, K. Census from heaven: An estimate of the global human population using nighttime satellite imagery. Int. J. Remote Sens. 2001, 22, 3061-3076.

52. Elvidge, C.D.; Imhoff, M.L.; Baugh, K.E.; Hobson, V.R.; Nelson, I.; Safran, J.; Dietz, J.B.; Tuttle, B.T. Night-time lights of the world: 1994-1995. ISPRS J. Photogramm. Remote Sens. 2001, 56, 81-99.

53. Small, C.; Pozzi, F.; Elvidge, C.D. Spatial analysis of global urban extent from DMSP-OLS night lights. Remote Sens. Environ. 2005, 96, 277-291.

54. Roychowdhury, P.K.; Maithani, S. Monitoring growth of built-up areas in indo-gangetic plain using multi-sensor remote sensing data. J. Indian Soc. Remote Sens. 2010, 38, 291-300.

55. Sutton, P.C.; Anderson, S.J.; Elvidge, C.D.; Tuttle, B.T.; Ghosh, T. Paving the planet: Impervious surface as proxy measure of the human ecological footprint. Prog. Phys. Geogr. 2009, 33, $510-527$. 
56. Yang, Y.; He, C.; Zhang, Q.; Han, L.; Du, S. Timely and accurate national-scale mapping of urban land in China using defense meteorological satellite program's operational linescan system nighttime stable light data. J. Appl. Remote Sens. 2013, 7, 073535-073535.

57. Lu, D.; Tian, H.; Zhou, G.; Ge, H. Regional mapping of human settlements in southeastern China with multisensor remotely sensed data. Remote Sens. Environ. 2008, 112, 3668-3679.

58. Cao, X.; Chen, J.; Imura, H.; Higashi, O. A SVM-based method to extract urban areas from DMSP-OLS and spot vgt data. Remote Sens. Environ. 2009, 113, 2205-2209.

59. Elvidge, C.; Safran, J.; Tuttle, B.; Sutton, P.; Cinzano, P.; Pettit, D.; Arvesen, J.; Small, C. Potential for global mapping of development via a nightsat mission. GeoJournal 2007, 69, 45-53.

60. Ebener, S.; Murray, C.; Tandon, A.; Elvidge, C. From wealth to health: Modelling the distribution of income per capita at the sub-national level using night-time light imagery. Int. J. Health Geogr. 2005, 4, doi:10.1186/1476-072X-4-5.

61. Takahashi, K.I.; Terakado, R.; Nakamura, J.; Daigo, I.; Matsuno, Y.; Adachi, Y. In-use stock of copper analysis using satellite nighttime light observation data. Mater. Trans. 2009, 50, 1871-1874.

62. Tian, J.; Zhao, N.; Samson, E.L.; Wang, S. Brightness of nighttime lights as a proxy for freight traffic: A case study of China. IEEE J. Sel. Top. Appl. Earth Obs. Remote Sens. 2014, 7, 206-212.

63. Sutton, P. Modeling population density with night-time satellite imagery and GIS. Comput. Environ. Urban Syst. 1997, 21, 227-244.

64. Sutton, P.C.; Elvidge, C.; Obremski, T. Building and evaluating models to estimate ambient population density. Photogramm. Eng. Remote Sens. 2003, 69, 545-553.

65. Elvidge, C.D.; Baugh, K.E.; Anderson, S.J.; Sutton, P.C.; Ghosh, T. The Night Light Development Index (NLDI): A spatially explicit measure of human development from satellite data. Soc. Geogr. 2012, 7, 23-35.

66. Elvidge, C.D.; Sutton, P.C.; Ghosh, T.; Tuttle, B.T.; Baugh, K.E.; Bhaduri, B.; Bright, E. A global poverty map derived from satellite data. Comput. Geosci. 2009, 35, 1652-1660.

67. Wang, W.; Cheng, H.; Zhang, L. Poverty assessment using DMSP/OLS night-time light satellite imagery at a provincial scale in China. Adv. Space Res. 2012, 49, 1253-1264.

68. Kiran Chand, T.R.; Badarinath, K.V.S.; Krishna Prasad, V.; Murthy, M.S.R.; Elvidge, C.D.; Tuttle, B.T. Monitoring forest fires over the Indian region using defense meteorological satellite program-operational linescan system nighttime satellite data. Remote Sens. Environ. 2006, 103, $165-178$.

69. Casadio, S.; Arino, O.; Serpe, D. Gas flaring monitoring from space using the ATSR instrument series. Remote Sens. Environ. 2012, 116, 239-249.

70. Kiyofuji, H.; Saitoh, S.-I. Use of nighttime visible images to detect Japanese common squid todarodes pacificus fishing areas and potential migration routes in the sea of Japan. Mar. Ecol. Prog. Ser. 2004, 276, 173-186.

71. Bankert, R.L.; Solbrig, J.E.; Lee, T.F.; Miller, S.D. Automated lightning flash detection in nighttime visible satellite data. Weather Forecast. 2011, 26, 399-408.

72. Kharol, S.K.; Badarinath, K.V.S. Impact of biomass burning on aerosol properties over tropical urban region of hyderabad, India. Geophys. Res. Lett. 2006, 33, L20801. 
73. Maxwell, M.R.; Henry, A.; Elvidge, C.; Safran, J.; Hobson, V.; Nelson, I.; Tuttle, B.; Dietz, J.; Hunter, J. Fishery dynamics of the California market squid (Loligo opalescens), as measured by satellite remote sensing. Fish. Bull. 2004, 102, 661-670.

74. Rayner, P.J.; Raupach, M.R.; Paget, M.; Peylin, P.; Koffi, E. A new global gridded data set of $\mathrm{CO}_{2}$ emissions from fossil fuel combustion: Methodology and evaluation. J. Geophys. Res. 2010, 115, D19306.

75. Ghosh, T.; Elvidge, C.D.; Sutton, P.C.; Baugh, K.E.; Ziskin, D.; Tuttle, B.T. Creating a global grid of distributed fossil fuel $\mathrm{CO}_{2}$ emissions from nighttime satellite imagery. Energies 2010, 3, 1895-1913.

76. Oda, T.; Maksyutov, S. A very high-resolution $(1 \mathrm{~km} \times 1 \mathrm{~km})$ global fossil fuel $\mathrm{CO}_{2}$ emission inventory derived using a point source database and satellite observations of nighttime lights. Atmos. Chem. Phys. 2011, 11, 543-556.

77. Letu, H.; Nakajima, T.Y.; Nishio, F. Regional-scale estimation of electric power and power plant $\mathrm{CO}_{2}$ emissions using defense meteorological satellite program operational linescan system nighttime satellite data. Environ. Sci. Technol. Lett. 2014, 1, 259-265.

78. Kort, E.A.; Frankenberg, C.; Miller, C.E.; Oda, T. Space-based observations of megacity carbon dioxide. Geophys. Res. Lett. 2012, 39, doi:10.1029/2012GL052738.

79. Wei, Y.; Liu, H.; Song, W.; Yu, B.; Xiu, C. Normalization of time series DMSP-OLS nighttime light images for urban growth analysis with pseudo invariant features. Landsc. Urban Plan. 2014, $128,1-13$.

80. Li, X.; Xu, H.; Chen, X.; Li, C. Potential of NPP-VIIRS nighttime light imagery for modeling the regional economy of China. Remote Sens. 2013, 5, 3057-3081.

81. Elvidge, C.; Zhizhin, M.; Hsu, F.-C.; Baugh, K. VIIRS nightfire: Satellite pyrometry at night. Remote Sens. 2013, 5, 4423-4449.

82. Miller, S.; Straka, W.; Mills, S.; Elvidge, C.; Lee, T.; Solbrig, J.; Walther, A.; Heidinger, A.; Weiss, S. Illuminating the capabilities of the Suomi National Polar-Orbiting Partnership (NPP) Visible Infrared Imaging Radiometer Suite (VIIRS) day/night band. Remote Sens. 2013, 5, 6717-6766.

83. Shi, K.; Yu, B.; Huang, Y.; Hu, Y.; Yin, B.; Chen, Z.; Chen, L.; Wu, J. Evaluating the ability of NPP-VIIRS nighttime light data to estimate the gross domestic product and the electric power consumption of China at multiple scales: A comparison with DMSP-OLS data. Remote Sens. 2014, 6, 1705-1724.

84. Shi, K.; Huang, C.; Yu, B.; Yin, B.; Huang, Y.; Wu, J. Evaluation of NPP-VIIRS night-time light composite data for extracting built-up urban areas. Remote Sens. Lett. 2014, 5, 358-366.

85. Hodler, R.; Raschky, P.A. Regional favoritism*. Q. J. Econ. 2014, 129, 995-1033.

86. Liang, H.; Tanikawa, H.; Matsuno, Y.; Dong, L. Modeling in-use steel stock in China's buildings and civil engineering infrastructure using time-series of DMSP/OLS nighttime lights. Remote Sens. 2014, 6, 4780-4800.

87. Cinzano, P.; Falchi, F. The propagation of light pollution in the atmosphere. Mon. Not. R. Astron. Soc. 2012, 427, 3337-3357.

88. Butt, M. Estimation of light pollution using satellite remote sensing and geographic information system techniques. GISci. Remote Sens. 2012, 49, 609-621. 
89. Han, P.; Huang, J.; Li, R.; Wang, L.; Hu, Y.; Wang, J.; Huang, W. Monitoring trends in light pollution in China based on nighttime satellite imagery. Remote Sens. 2014, 6, 5541-5558.

90. Bennie, J.; Davies, T.W.; Duffy, J.P.; Inger, R.; Gaston, K.J. Contrasting trends in light pollution across Europe based on satellite observed night time lights. Sci. Rep. 2014, 4, 3789.

91. Li, X.; Chen, F.; Chen, X. Satellite-observed nighttime light variation as evidence for global armed conflicts. IEEE J. Sel. Top. Appl. Earth Obs. Remote Sens. 2013, 6, 2302-2315.

(C) 2014 by the authors; licensee MDPI, Basel, Switzerland. This article is an open access article distributed under the terms and conditions of the Creative Commons Attribution license (http://creativecommons.org/licenses/by/3.0/). 